
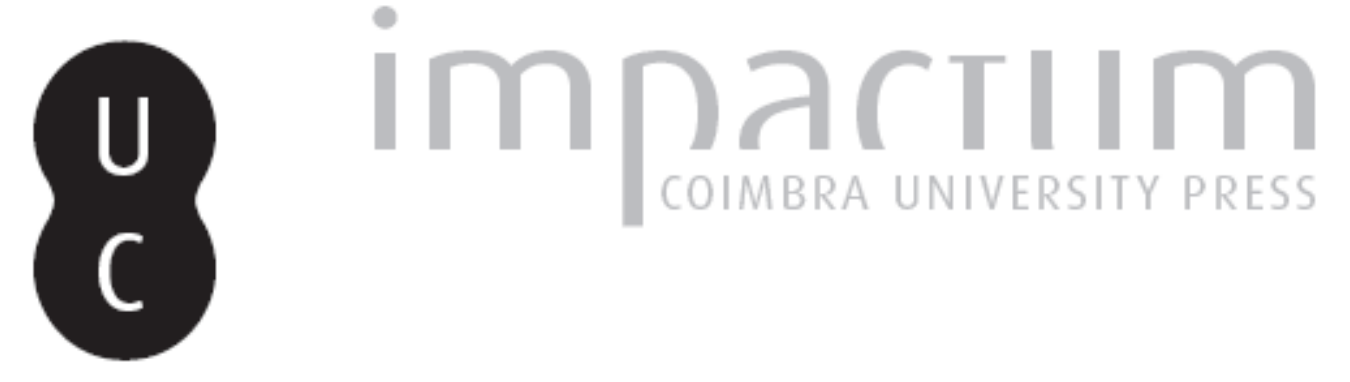

Espaço e narrativa em P. Ricoeur

Autor(es): $\quad$ Umbelino, Luís António

Publicado por: Faculdade de Letras da Universidade de Coimbra, Instituto de Estudos Filosóficos

URL persistente:

URI:http://hdl.handle.net/10316.2/29610

DOI: DOI:http://dx.doi.org/10.14195/0872-0851_39_5

Accessed : $\quad$ 26-Apr-2023 12:52:00

A navegação consulta e descarregamento dos títulos inseridos nas Bibliotecas Digitais UC Digitalis, UC Pombalina e UC Impactum, pressupõem a aceitação plena e sem reservas dos Termos e Condições de Uso destas Bibliotecas Digitais, disponíveis em https://digitalis.uc.pt/pt-pt/termos.

Conforme exposto nos referidos Termos e Condições de Uso, o descarregamento de títulos de acesso restrito requer uma licença válida de autorização devendo o utilizador aceder ao(s) documento(s) a partir de um endereço de IP da instituição detentora da supramencionada licença.

Ao utilizador é apenas permitido o descarregamento para uso pessoal, pelo que o emprego do(s) título(s) descarregado(s) para outro fim, designadamente comercial, carece de autorização do respetivo autor ou editor da obra.

Na medida em que todas as obras da UC Digitalis se encontram protegidas pelo Código do Direito de Autor e Direitos Conexos e demais legislação aplicável, toda a cópia, parcial ou total, deste documento, nos casos em que é legalmente admitida, deverá conter ou fazer-se acompanhar por este aviso.

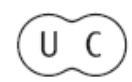




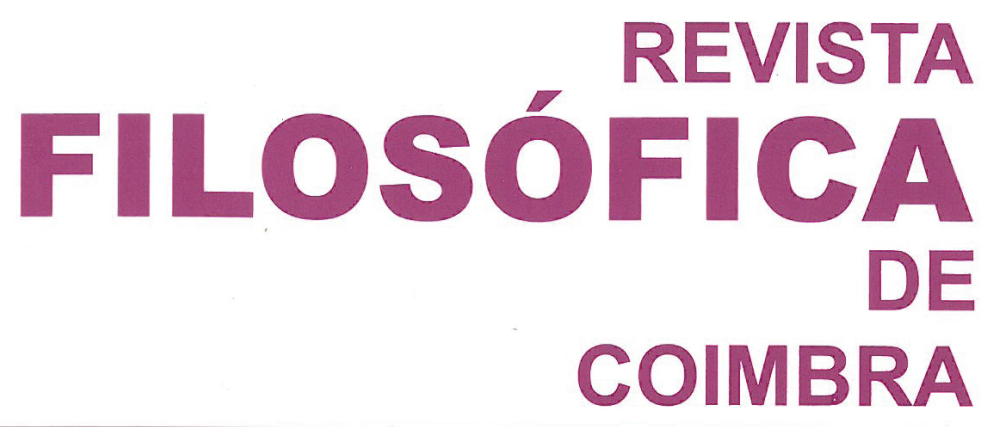

vol. 20 - número 39 - março 2011

vol. 20 - número 39 - março 2011

Fundação Eng. António de Almeida

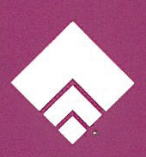




\title{
ESPAÇO E NARRATIVA EM P. RICOEUR
}

\author{
LUÍS ANTÓNIO UMBELINO ${ }^{1}$
}

\begin{abstract}
This paper aims to mediate on the sense and philosophical implications of the following proposal made by Ricoeur in Memory, History, Forgiveness: in order to think an human space we have to transfer to an architectural plan of analysis the elements of the triple mimesis developed in Time and Narrative. Ricoeur thus seem to offer his readers an opportunity to consider, from the centre of his hermeneutic project, the problem of space.
\end{abstract}

Key-words: Mimesis, Time, Space, Architecture, City.

Résumé: C'est notre intention, dans le travail ici présenté, de méditer au sens et aux implications de l'indication suivante proposée par P. Ricoeur dans La mémoire, l'histoire, l'oubli: si on veut méditer l'espace humain il faut faire la transposition au plan architectural des catégories liées à la triple mimèsis exposée dans Temps et récit. Ricoeur semble, de ce fait, offrir à ses lecteurs des indications précieuses pour méditer, au centre de son projet herméneutique, le problème de l'espace.

Mots-clé : Mimèsis, Temps, Espace, Architecture, Ville.

\section{O destino do tempo e o destino do espaço.}

“Soyons les flâneurs des lieux de mémoire»². É com estas palavras,

${ }^{1}$ Departamento de Filosofia, Comunicação e Informação da F.L.U.C.

2 O presente texto retoma algumas das teses centrais por nós formuladas numa comunicação intitulada "Herméneutique et Architecture des lieux de mémoire", apresentada ao Colóquio Internacional "Reading Ricoeur once again", que teve lugar na Universidade Nova de Lisboa nos dias 22, 23 e 24 de Outubro de 2009. Aqui se retomam igualmente algumas das reflexões esboçadas em "Filosofia do Espaço e Arquitectura", comunicação 
intensas e significativas, que P. Ricoeur, na esteira de W. Benjamin, encerra um artigo publicado em 1998 na revista Urbanisme com o título «Architecture et narrativité». A expressão é sugestiva: o flanêur, esse vagabundo das paisagens urbanas que deambula sem motivo, que não procura senão submergir nos fluxos de movimento citadino, senão perderse no labirinto das ruas e entregar-se aos desígnios do acaso, é também aquele que, em acto, associa o destino do espaço ao destino do tempo e o destino do tempo aos percursos - ao tecido - da cidade. Tal insinuação teórica ganha particular interesse sob a pena de um filósofo que longamente meditou o tempo e nos instigou a pensá-lo, nomeadamente, através do tema da narratividade - que no texto em questão surge prometedoramente associado à arquitectura. Ora, que aquela figura do flanêur, com a sua vivência de uma mistura entre "lugar" e "memória", encerre um estudo onde a narratividade surge associada a um saber do espaço não poderia deixar de confrontar o leitor de Ricoeur com uma questão pouco habitual: a que ponto as relações entre tempo, narrativa, memória e história, centrais no contexto da obra monumental do filósofo de Valence, reclamam uma hermenêutica do espaço - melhor: a que ponto algo nessas relações reclama a via longa de uma hermenêutica do espaço que complete a interpretação da temporalidade através do arquitectural e do urbanístico, do geográfico e do histórico, do construído e reconstruído?

Nesta ocasião gostaríamos de tentar mostrar que a chave para levar a bom termo tal via necessária de investigação é, justamente, o que Ricoeur nos pretende oferecer em "Architecture et narrativité ». Este texto, pouco estudado mas de raro interesse, de facto, permite-nos ligar, precisamente através do tema do espaço, a trilogia de Temps et récit (1983-85) e o texto de La mémoire, l'histoire, l'oubli (2000), assim rasgando no horizonte da meditação ricoeuriana sobre a temporalidade da condição humana fios incontornáveis de uma investigação aprofundada da espacialidade que lhe corresponde. Dir-se-ia que Ricoeur nos conduz até aos estimulantes lugares de fronteira onde se entrecruzam meditação filosófica, arquitectura e urbanismo. Efectivamente, em "Architecture et narrativité »o filósofo propõe-se - o que é imediatamente sugerido pelo título - desenvolver uma análise do espaço construído da arquitectura em tudo análoga à análise do tempo contado desenvolvido em Temps et récit, sendo que esta possibilidade é expressamente retomada (o artigo da Revista Urbanisme é citado) num momento importante de La mémoire, l'histoire, l'oubli dedicado à análise do "espaço habitado", primeiro passo de um estudo

apresentada na sessão do ciclo de conferências "As Artes do Colégio" (uma organização do Colégio das Artes) que teve lugar em Coimbra, no dia 14 de Janeiro de 2011.

RICOEUR, P., “Architecture et narrativité”, in Urbanisme, no 303 (1998), p. 51. 
da "memória arquivada"”. Nesta articulação, um ponto de partida para a análise é claramente enunciado: o destino do tempo e o destino do espaço - do tempo humano e do espaço humano - estão ligados e tal ligação chama renovadamente a pensar.

\section{O tempo humano}

O modo como Ricoeur se propôs pensar, de forma renovada, as condições de compreensão do tempo propriamente humano encontra um momento decisivo de explanação ao longo dos três volumes de Temps et Récit. O pressuposto que, nesse contexto, orienta a investigação liga-se ao reconhecimento da realidade fundamentalmente temporal da condição humana, e pretende enfrentar a dificuldade colocada pela impossibilidade de um acesso directo a tal realidade. Num certo sentido, orienta a investigação ricoeuriana a velha questão agostiniana: “o que é o tempo?" - esse tempo que sei ser o meu no silêncio de qualquer pergunta, mas se furta a qualquer questionamento que o demande directamente. Como sempre fez, Ricoeur, num labor filosófico de envergadura, visitará, na tentativa de enfrentar tal dificuldade, as grandes concepções clássicas (Aristóteles e Agostinho, Husserl, Heidegger e Kant) que acolhem sobre o problema do tempo as indicações mais férteis e vigorosas. E em redor de tal questão do tempo humano descobrirá, antes de mais, uma aporética onde mutuamente se tentam eliminar uma concepção de "tempo cósmico" ou tempo do mundo - série uniforme e indiferenciada de momentos sequencialmente ordenados - e a concepção de um "tempo da alma" ou tempo vivido, de um tempo puramente fenomenológico (a distencio animi já descrita por Agostinho ${ }^{4}$ ) - que varia em intensidade, conforme o modo como os acontecimentos são vividos por quem faz a sua experiência diferenciada e significativa ${ }^{5}$.

Para Ricoeur, o tempo humano não se encontrará sem antes se ultrapassar tal aporia, ou melhor, sem a fazer jogar produtivamente. Através de uma estratégia de ligação, através de "procedimentos de conexão", há que desvendar, nos nós de ligação entre tempo do mundo e tempo vivido, um terceiro tempo, um tempo que, justamente, apenas se desvenda na

${ }^{3}$ RICOEUR, P., La mémoire, l'histoire, l'oubli, Seuil, Poche Essais, 2000, pp. 183 e ss.

${ }^{4}$ Cf. RICOEUR, P., Temps et récit III, Seuil, Paris, 1986, pp. 19 e ss.

${ }^{5}$ Ibidem, p. 11: «Les cinq chapitres de cette section se concentrent sur la difficulté principale que l'aporétique aura dégagée, à savoir l'irréductibilité l'une à l'autre, voir l'occultation l'une par l'autre, d'une perspective purement phénoménologique sur le temps et d'une perspective adverse que, pour faire bref, j'appelle cosmologique.» 
mistura desses outros dois tempos. Neste sentido, deve compreender-se que o tempo humano apenas se revela quando, na homogeneidade do tempo do mundo, o tempo de uma vida se chega a inscrever.

Que tal seja possível é confirmado, nomeadamente, pelo exemplo do calendário ${ }^{6}$. Através do calendário, o tempo vivido pode ser inscrito no tempo cósmico, quando em alguns dias se assinalam datas de aniversário, promessas de encontro ou celebrações. Neste gesto, a escala desmesurada do tempo cósmico é humanizada e, simultaneamente, o tempo vivido recebe algo como uma referência que o $\operatorname{cosmologiza}{ }^{7}$. Num tempo que não faço e passa sequencialmente, a minha vida marca-se ao ser sublinhada a diferença de algumas datas, salientada a importância e o significado de certos períodos que, assim, passam a marcar uma relação peculiar ao tempo: uma data especial aguarda-se na experiência de um tempo que "nunca mais chega", ou celebra-se na recordação de um momento que se reactualiza porque não se quer perder. Seja como for, esses dias não são "normais", mas "especiais", não são "um dia qualquer", ou "mais um dia" mas "aquele" dia. A intensidade de tais datas, o modo como esburacam o tempo do mundo, como o tomam sem o dissolver, tornam possível um encontro com a real condição temporal da vida humana. Mas, justamente, esse encontro acontece porque - tese central de Ricoeur -, por essas inscrições, aquilo que realmente se desvenda é uma vida que se quer contar. Uma data importante assinalada no calendário, para voltarmos uma última vez a este exemplo, só me dá a temporalidade do meu existir se eu for capaz de dizer algo como: "faz hoje dez anos que...", ou "está a chegar o aniversário de...". É, pois, necessário que as datas assinaladas no calendário se articulem de modo coerente para mim e, nessa coerência, me "tragam" algo do tempo da minha própria vida. Assim, deve dizer-se que é a capacidade de contar a "minha" história que desvenda a "minha" condição temporal. Numa palavra, é a narrativa a verdadeira forma de aceder ao tempo humano (e, assim, de superar as aporias na qual permanece enredada uma fenomenologia do tempo). Aquele terceiro tempo, o tempo propriamente humano que Ricoeur demanda, apenas se encontra, então, quando uma narrativa de vida se começa. É este, julgamos, um ponto decisivo do debate que subjaz a Temps et récit.

Segundo Ricoeur, "existe entre a actividade de contar uma história e o carácter temporal da experiência humana uma correlação que não

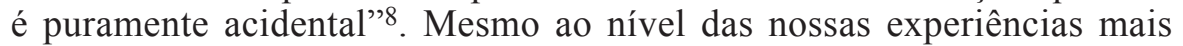
simples e quotidianas, a nossa existência não se torna a nossa senão

\footnotetext{
${ }^{6}$ RICOEUR, P., Temps et récit I, Seuil, Paris, 1983, p. 85.

${ }^{7}$ RICOEUR, P., Temps et récit III, pp. 154 e ss.

${ }^{8}$ RICOEUR, P., Temps et récit $I$, p. 85.
} 
no tempo; mas, justamente, a nossa existência não se torna temporal senão através da síntese de integração que a narrativa é capaz de operar na sucessão do que nos acontece. Ricoeur di-lo claramente numa frase já celebrizada pelos seus comentadores: "o tempo torna-se tempo humano na medida em que é articulado de um modo narrativo", sendo que, consequentemente, deve notar-se que "a narrativa alcança a sua significação plena quando se torna condição da existência temporal." 9 É que apenas a narrativa, com a sua vocação de ordenar o discordante, de homogeneizar o heterogéneo, oferece a possibilidade de configuração e reconfiguração criadora de acontecimentos dispersos num todo coerente, numa história; e apenas deste modo o tempo humano se torna possível - tempo que, então, se desvenda no ponto de ruptura e de sutura entre o tempo cósmico e o tempo vivido.

Apenas as tramas da narrativa permitem, segundo Ricoeur, pensar a nossa temporalidade (a nossa historicidade) face à impossibilidade de uma reflexão pura sobre o tempo; mais precisamente, só a intriga que a narrativa põe em cena permite compreender a experiência do tempo humano, aquele onde cada um se pode reapoderar da sua própria condição humana através da ordenação possível dos eventos dispersos que lhe sobrevêm.

A importância e centralidade desta articulação entre tempo e narrativa no contexto da obra de Ricoeur é suficientemente conhecida para nos dispensar de mais referências. Neste momento apenas gostaríamos de realçar um ponto preciso: Ricoeur não deixará de associar, na sua reflexão, tempo, narrativa e espaço. E tal facto não poderia deixar de chamar a atenção. O filósofo de Valence sustentará claramente em La mémoire, l'histoire, l'oubli que o destino deste tempo narrativo, deste tempo humanizado pela articulação significativa de eventos, está sempre unido ao destino de um espaço. E, de facto, não será sempre num espaço que se movimentam as personagens de qualquer narrativa ${ }^{10}$, seja na nossa narrativa quotidiana, seja nas grandes narrativas históricas e de ficção?

Ao nível das nossas experiências quotidianas, um exemplo esclarecedor deste entrecruzamento de tempo e espaço pode ser encontrado através de todas aquelas experiências de memória que resumimos na afirmação "eu estava lá"11; o imperfeito gramatical dá-nos a medida do tempo passado no presente da afirmação e na promessa de uma história que se começa

${ }^{9}$ Ibidem, 1. c. Cf., para um esclarecimento do aqui essencial, PORTOCARRERO, M. L. Horizontes da Hermenêtica em Paul Ricoeur, Ariadne, Coimbra, 2005, pp. 60 e ss. ID, "Narrativa e Configuração de Identidade em Paul Ricoeur", in HENRIQUES, F. (coord.), A Filosofia de Paul Ricoeur, Ariadne, Coimbra, 2006, pp.269 e ss.

${ }^{10}$ RICOEUR, P., La mémoire, l'histoire, l'oubli, p. 183.

${ }^{11}$ Ibidem, 1. c. 
assim a narrar; o advérbio marca o enraizamento espacial desse momento passado, assim ligando ao enraizamento espacial o carácter declarativo de uma memória que se inscreveu em lugares determinados e, precisamente por isso, pode sustentar uma história que permite dizer aos outros o que vivi e esperei. Mas não é apenas a este nível quotidiano da experiência individual que encontraremos a confirmação do destino partilhado pelo tempo e pelo espaço. Igualmente no plano mais profundo da análise histórica se surpreende a presença constante do espaço. Esta presença da contrapartida espacial do tempo histórico, julgamos, é o que Ricoeur pretende sublinhar no momento em que medita a concepção de "geohistória" da escola dos Annales. Nesta lê Ricoeur todo um programa de trabalho que, cruzando uma cartografia da permanência com uma geopolítica da longa duração ${ }^{12}$, torna evidente a malha espacio-temporal dos acontecimentos históricos. A este propósito Ricoeur destacará os trabalhos de Fernand Braudel sobre La Méditerranée et le Monde méditerranéen à l'époque de Phillippe II, por neles encontrar demonstrado algo de decisivo: que o meio (milieu) e o espaço são "termos equivalentes" e que o meio nunca deixa de ser um espaço de vida e de civilização ${ }^{13}$.

Mas que espaço é este de que assim se fala? A resposta só pode ser aqui uma: um espaço propriamente humano. E onde se pode encontrar tal espaço? A resposta a esta questão derradeira marca a originalidade da análise de Ricoeur que aqui seguimos de perto: para encontrar o espaço humano é necessário, ensina o nosso filósofo, fazer jogar produtivamente - seguindo um processo análogo ao que foi necessário seguir para encontrar o tempo humano - as aporias, em tudo simétricas às aporias do tempo, que opõem e tendem a ocultar mutuamente uma concepção de espaço geométrico e uma concepção de espaço vivido. Apenas superando tais aporias, apenas provocando as suas fronteiras ilusoriamente definitivas se desvendará, de facto, o que faz a ponte entre elas, ou talvez melhor, o que em cada concepção já contagia desde sempre positivamente a outra. E, de novo, como em relação ao tempo, apenas nesse ponto de ruptura e de sutura se encontrará um "terceiro espaço", o espaço de vida onde uma vida pode ter lugar.

\section{O "terceiro" espaço}

A oposição entre uma concepção de espaço geométrico e uma concepção de espaço vivido nasce da constatação de que a concepção moderna de um espaço matemático, projectado como homogéneo, uniforme, isotrópico e

12 RICOEUR, P., La mémoire, l'histoire, l'oubli, p. 189.

13 Ibidem, 1. c. 
infinito, está longe de exaurir a experiência que, enquanto corpo, fazemos do espaço, longe de poder anular o saber do espaço que ressoa através da nossa corporeidade. Do mesmo modo que em relação ao tempo se distinguiu entre "tempo do mundo", mensurável, sequencial, indiferente e homogéneo, e um "tempo vivido" onde as tradicionais dimensões do tempo se experimentam em infindáveis variações de intensidade e reciprocidade, assim também haverá lugar a distinguir entre a concepção de um espaço exterior ou espaço do mundo e um espaço vivido ou fenomenológico.

Sobre o espaço vivido, permanecemos, segundo Ricoeur, devedores das magníficas análises que, desde logo na sua Phénoménologie de la perception - inspiradas, nomeadamente, pelos trabalhos percursores de E. Minkowski - Merleau-Ponty dedicou ao tema. Sob a designação de espaço vivido pretendeu Merleau-Ponty estudar a realidade de um significativo pacto ante-predicativo arcaico porque mais antigo do que o pensamento - pelo qual corpo e espaço se tomam desde sempre a cargo. Dito de outro modo, interessa ao fenomenólogo francês demonstrar a que ponto as nossas experiências originárias do corpo e da corporeidade desenrolam um espaço que parece convocar imemorialmente o movimento e as disposições do corpo. A sua tese, neste contexto, é decisiva: "a série das nossas experiências, até à primeira, transmitem uma espacialidade já adquirida." 14 Esta aquisição, no entanto, não releva de uma qualquer capacidade gnosiológica ou representativa; a espacialidade de que o corpo próprio guarda o segredo é recebida por meio de uma secreta e rica praktognosia ${ }^{15}$ pela qual o corpo co-responde dinamicamente a um espaço que o envolve e atravessa, e que nesse atravessar contribui para o situar. A situação do corpo desvenda-se, então, primitivamente nesses nós vividos de um espaço onde "entre o meu corpo como potência de certos gestos, como exigência de certos planos privilegiados, e o espectáculo percebido como convite aos mesmos gestos e teatro das mesmas acções, se estabelece um pacto que me dá a fruição do espaço como às coisas poder directo sobre o meu corpo." 16 Merleau-Ponty pretende mostrar, deste modo, que a fenomenalidade do espaço vivido tem a ver com o modo de habitar do corpo que somos - desse corpo que é "unidade aberta", "expressividade recíproca das partes" que deve reconhecer-se exactamente correlativa da "unidade aberta e não tematizável, unidade de

${ }^{14}$ MERLEAU-PONTY, M., Phénoménologie de la perception, Gallimard, Paris, 1945, p. 293.

15 Ibidem, p. 164: “L'expérience motrice de notre corps n'est pas un cas particulier de connaissance; elle nous fournit une manière d'accéder au monde et à l'objet, une 'praktognosie' qui doit être reconnue comme originale et peut-être comme originaire".

16 Ibidem, p. 289. 
estilo mais do que de significado, que caracteriza o mundo" 17 . Mergulhado no espaço, percorrendo desde sempre o seu interior, o corpo desvenda-se como verdadeiro "nó de significações vivas" e não como "lei de um certo número de termos co-variantes" 18 ; ele é esse ponto cego que, percorrendo o tecido do espaço, restitui a direita e a esquerda, o alto e o baixo, o longe e o perto, que desenrola posturas e carrega o espaço de forças que marcam o modo como as coisas contam para ele. $\mathrm{O}$ espaço do corpo é desenrolado ao longo de eixos de interesse, preenchido por zonas qualitativamente diferentes, orientado por formas significativas.

Se de alguma comprovação adicional carecessem estas últimas considerações, bastaria recordar todo o conjunto de distintas intensidades que se inserem no espaço através, justamente, da direita e da esquerda do corpo, do alto e do baixo, do "à frente" e "atrás", do "de pé" ou "de joelhos", do "perto" e do "longe"19. Todas estas coordenadas do espaço têm por medida incomensurável a postura do próprio corpo que, assim, parece devolver ao espaço uma justa correspondência orientadora: recorde-se o significado de "dar" a minha direita, de aceitar quem me critica "pela frente" (o valor da "frontalidade") e ignorar quem o faz "pelas costas", de "erguer-me" ante as dificuldades, ou não me deixar "rebaixar" - todas estas expressões são outras tantas confirmações de que, enquanto corpo, não estou no espaço à maneira de um simples objecto, mas desde sempre a ele unido.

O espaço não existe para o corpo que sou, seja em que momento for, como uma realidade separada. Espaço e corpo não existem, enquanto próprios e vividos, senão imbricados. É justamente esta evidência de um espaço que se desenrola através do corpo e de um corpo desde sempre envolvido no espaço que Merleau-Ponty se propôs investigar. Esse imbricamento é, no entanto, o mais difícil de pensar; ele é a nossa própria condição, a nossa própria circunstância corporal. Em rigor, pois, o "lugar" do corpo em tal espaço vivido (espaço percebido no movimento do corpo, antes e independentemente de qualquer consideração de extensão ou medida) deve ser entendido como sinónimo de uma essencial adesão e equivalência pré-pessoal (anónima) à forma geral do mundo - adesão corporal que é essencialmente não-coincidência, abertura, excesso, movimento imbricado na profundidade, conluio activo com o que orienta cada gesto.

17 BARBARAS, R., Le tournant de l'expérience. Recherches sur la philosophie de Merleau-Ponty, Vrin, Paris, 1998 p. 116.

18 MERLEAU-PONTY, M., Phénoménologie..., p. 117 : «C'est en ce sens que notre corps est comparable à l'œuvre d'art. Il est un nœud de significations vivantes et non pas la loi d'un certain nombre de termes covariants.»

19 Cf. BOLLNOW, O. F., Hombre et espacio (trad. esp.) Biblioteca Universitaria Labor, Barcelona, 1969, pp. 49 e ss. 
Tais considerações sobre um espaço "sensível ao coração" 20 - expressão de J. Paulhan que Merleau-Ponty assume - permanecerão estranhas a todas as doutrinas clássicas que, sob o primado de uma geometrização abstracta e axiomática, perseguem uma ideia de espaço infinito, homogéneo, isotrópico, onde, necessariamente, "o sujeito abandona [...] o seu lugar, o seu ponto de vista sobre o mundo e passa[...] a pensá-lo numa espécie de ubiquidade." ${ }^{21}$ Como mostra Merleau-Ponty, a fenomenalidade deste espaço vivido não resulta, de facto, de um qualquer sistema de determinações matemáticas e geométricas, antes reclamando, para ser dito, um outro discurso distinto do paradigma euclidiano e das concepções modernas que reduzem o espaço a mais um objecto integralmente disponível.

É neste vivido do espaço, assim meditado pelo autor da Phénoménologie de la perception através das alternâncias e intensidades que marcam o modo como o corpo próprio está no seu lugar, que Ricoeur reconhece o tecido primitivo da nossa relação ao espaço: esta está ancorada, de facto, no modo de participação ou pertença pelo qual o espaço é vivido pelo corpo antes de ser tematizado. Consequentemente, pode dizer-se que nesse modo de pertença se encontra a primitiva referência do acto de habitar. No entanto, ante esta concepção de espaço vivido, definido a partir de uma clara distinção em relação ao espaço "objectivo" e mensurável, importa segundo Ricoeur perguntar ainda se entre esses "dois" espaços não haverá, efectivamente, qualquer relação. É certo, e Ricoeur não o ignora, que para dizer o espaço vivido é necessário encontrar "um discurso prévio ao do espaço euclidiano, cartesiano, newtoniano"22. Mas será que tais espaços - vivido e objectivo - apenas se podem conceber como radicalmente heterogéneos? Ou mais precisamente: será que é o espaço vivido a única referência do habitar? Será que habitamos apenas num espaço vivido que exclui qualquer relação com um espaço "exterior", com um espaço cujas dimensões não são desenroladas pelo corpo? Não será antes verdade que o espaço humano, o espaço onde se habita humanamente, é um espaço onde o vivido se mistura com referências - ainda que imaginadas, ainda que sonhadas - de um espaço construído?

As belas descrições fenomenológicas do imaginário do espaço vivido, propostas por G. Bachelard em La poétique de l'espace, são, a este respeito, importantes. Bachelard trabalha com a ideia de que o acto de habitar "tem as suas próprias polaridades" e intensidades. Atento a umas como a outras, procura descrevê-las, nomeadamente, em termos de "residir, deslocar-

${ }^{20}$ Cf. MERLEAU-PONTY, M., Causeries. 1948. Seuil, Paris, 2002, p. 22.

${ }^{21}$ MERLEAU-PONTY, M., Phénoménologie..., p. 295.

22 RICOEUR, P., La mémoire, l'histoire, l'oubli, p. 185. 
se, abrigar-se sob um tecto, atravessar um limiar e ir para o exterior." 23 As intensidades desenroladas pelo corpo no espaço aparecem, então, expressamente ligadas à casa, às suas divisões e aos objectos que contém, às relações entre o interior e o exterior que promove, às janelas, à cave, ao sótão; e tanto aquelas intensidades como estes "lugares" fazem jogar todo um conjunto significativo de dimensões da nossa espacialidade: refúgio, conforto, intimidade, protecção, abertura. Assim, sem casa, sem o "nosso" quarto, ou o nosso "canto", sem os armários e estantes onde se arruma uma vida, sem as gavetas onde se pode procurar o tempo perdido, a nossa intimidade "não teria modelo" 24 e o espaço vivido não teria, qualquer ponto de ancoragem. Dir-se-ia haver aqui uma mútua incorporação: o corpo vive, sonha, imagina, recorda em cada gesto uma casa que transcende o espaço geométrico com as suas zonas de "irrealidade" e memória que de modo algum se resumem a considerações de medida; a casa, por seu lado, - as suas regiões, os seus recantos, os seus contornos - também se encontra "fisicamente inserida em nós", como mostra Bachelard ao invocar o exemplo da casa de infância que se mistura em nós ao ponto de se transformar num "conjunto de hábitos orgânicos". Se a visitássemos "após vinte anos, apesar de todas as escadas anónimas, redescobriríamos os reflexos da "primeira escada', não tropeçaríamos num degrau um pouco alto. Todo o ser da casa se desdobraria, fiel ao nosso ser." 25

O espaço fenomenológico é, pois, mais do que apenas o espaço desenrolado pelo corpo. Dir-se-ia, assim, que o modo de presença do corpo no espaço, em rigor, não pode ser dito, nem pensado, "nem mesmo, no limite, experimentado sem uma qualquer referência, pelo menos alusiva, aos pontos, linhas, superfícies, volumes, distâncias, inscritos sobre um espaço desligado da referência ao aqui e ali inerentes ao corpo próprio." 26

Se pertencemos ao espaço pelo nosso corpo, é necessário considerar que esta pertença implica um jogo de localizações e de deslocações, de relações às coisas e aos outros corpos num espaço que guarda forçosamente dimensões, relações de distância e de volume que são exteriores ao corpo - no sentido em que não são desenroladas por ele, ainda que nelas se fixe esse desenrolar. Assim, deve concluir-se que habitamos um espaço vivido que pressupõe já e sempre, ainda que seja implicitamente (ainda que seja sonhado ou imaginado), um entrecruzamento com o espaço das casas do mundo.

\footnotetext{
${ }^{23}$ BACHELARD, G., La poétique de l'espace, P.U.F., Paris, 1957, p. 83.

24 Ibidem, 1. c.

25 Ibidem, p. 32.

${ }^{26}$ RICOEUR, P., La mémoire, l'histoire, l'oubli, p. 185.
} 
Se o nosso interesse for o de procurar o espaço humano, será necessário começar por esclarecer como - onde - se faz a ponte entre as concepções, sempre assumidas equivocamente como antagónicas, do espaço do corpo e do espaço do mundo; dito de outro modo, se quisermos compreender onde habitamos de facto, é forçoso resolver a aporética do espaço vivido e do espaço geométrico, enquanto tal aporética permanece a afirmação da irredutibilidade destes dois espaços, ou seja, da sua mútua ocultação. Segundo Ricoeur, devemos compreender, enfim, em que medida o espaço humano apenas se pode compreender "nos confins do espaço vivido e do espaço geométrico"27. Como em relação ao tempo, será, para tanto, necessário fazer jogar produtivamente a aporia para encontrar um "terceiro espaço": o espaço que nasce da mistura dos espaços referidos e que deve ser entendido como o espaço que, de facto, habitamos humanamente. E, para Ricoeur, este espaço que habitamos de modo humano não é senão o espaço desvendado pelo acto arquitectural de construção 28 . "É a arquitectura (...) que traz à luz a notável composição que formam em conjunto o espaço geométrico e o espaço desenrolado pela condição corporal." ${ }^{29} \mathrm{O}$ espaço construído da arquitectura faz a mediação entre ambos: "geometriza" as referências do espaço vivido desenrolado pelo corpo e, no mesmo gesto, "humaniza" as coordenadas objectivas e tridimensionais da geometria para as transformar em "lugares de vida". Tudo se passa como se o vivido do espaço encontrasse a sua expressão coerente nas inscrições que a construção arquitectural torna possível, e como se, reciprocamente, a construção geométrica do espaço acolhesse no seu centro as orientações corporais primitivas da relação ao espaço para lhes dar forma coerente. Levemos até ao fim o que, deste modo, se torna evidente: o espaço habitado, considerará Ricoeur, encontra-se sempre num "sítio" que é um nó de espaço construído, do mesmo modo que qualquer "presente" é um nó do tempo narrativo" 30 ; dito de outro modo: a relação da arquitectura ao espaço - eis a tese que o filósofo de Valence se propõe defender - deve ser entendida "ao mesmo nível" da relação da narrativa ao tempo" 31 e só assim se tornará efectivamente compreensível o que está em causa nas relações entre o habitar e o construído.

${ }^{27}$ Ibidem, p. 186.

${ }^{28}$ Ibidem, 1. c.

${ }^{29}$ Ibidem, 1. c.

${ }^{30}$ RICOEUR, P., “Architecture et narrativité”, p. 45

${ }^{31}$ RICOEUR, P., La mémoire, l'histoire, l'oubli, p. 186 «Quant à l'acte de construire, considéré comme une opération distincte, il faut prévaloir un type d'intelligibilité de même niveau que celui qui caractérise la configuration du temps par la mise en intrigue.» 


\section{Narratividade e Arquitectura}

Ricoeur constata haver um "paralelismo estreito" entre o tempo narrado e o espaço construído, entre arquitectura e narratividade. O filósofo é claro a este respeito: "a arquitectura está para o espaço como a narrativa está para o tempo, a saber, como operação "configurante" "32. De facto, afigura-se a Ricoeur semelhante a vocação que ambas, a narrativa e a arquitectura, manifestam para inscrever - a narrativa na duração, a construção arquitectural na durabilidade do material ${ }^{33}$ - o modo humano de habitar e estar temporalmente no mundo. Nesta ligação entre narratividade e arquitectura se encontra, a nosso ver, o núcleo mais original e fértil da meditação ricoeuriana sobre o problema do espaço.

De facto, é tal aproximação que permite a Ricoeur encetar um triplo aprofundamento decisivo da análise do espaço humano que lhe permite ultrapassar, nomeadamente, as célebres análises de M. Heidegger no seu artigo "Bauen, Wohnen, Denken" ${ }^{4}$ (texto que, como o trabalho de Bachelard atrás referido, exerceu uma influência significativa, nomeadamente durante os anos 80, sobre a teoria da arquitectura): num primeiro momento, devemos esclarecer a que ponto o habitar é o pressuposto do construir, como mostra Heidegger ${ }^{35}$; num segundo momento, é necessário compreender, no entanto, que o construir sempre "toma a cargo o habitar"; finalmente, torna-se forçoso considerar em que medida é que, quando o construído toma a cargo o habitar, se cria, enfim, a ocasião para que "a última palavra seja dada a um habitar reflectido, um habitar que refaz a memória do construir." ${ }^{36} \mathrm{E}$ assim sendo, se a narrativa é a operação pela qual o tempo se torna tempo humano, do mesmo modo que o edificar arquitectónico é a operação pela qual o espaço se torna espaço humano, importa ainda investigar a que ponto o paralelismo evidenciado representará antes uma imbricação, "um verdadeiro

\footnotetext{
32 RICOEUR, “Architecture et narrativité", p. 44.

33 RICOEUR, P., La mémoire, l'histoire, l'oubli, 187

34 HEIDEGGER, M., "Bâtir, habiter, penser", in ID, Essais et conférence, (trad. francesa), Gallimard, Paris, 1958,

35 Ibidem, p. 171. Não habitamos por ter construído, mas justamente o contrário: construímos porque somos seres que habitam. Apenas assim, de facto, se poderá compreender, segundo Heidegger, a que ponto na casa, por exemplo, "reside a relação do lugar e do espaço", e também "a relação do lugar ao homem que nele se demora." O construído deve, assim, respeitar o lugar, a terra onde se enraíza o nosso pensamento. E nesta vinculação algo mais se tornará claro: que tal como o pensamento, o construído pode ser uma clareira do ser do espaço: revela-o no seu fundo habitável, torna-o pensável enquanto lugar de pertença.

36 RICOEUR, P., “Architecture et narrativité”, p. 45.
} 
entrecruzamento", uma "mistura entre a configuração arquitectural do espaço e a configuração narrativa do tempo." 37

Para testar esta possibilidade, Ricoeur tentará mostrar que a arquitectura e o urbanismo operam em relação ao espaço uma tripla mimesis em tudo análoga à operada pela narrativa em relação ao tempo - e que Ricoeur, como é sabido, meditou em Temps et récit através de uma reinterpretação da tríade muthos-mimesis-catharsis da Poética de Aristóteles ${ }^{38}$.

Mimèsis I designa a pré-compreensão, a "prefiguração"39, na vida quotidiana, da qualidade narrativa da experiência, isto é, o facto de a vida, e ainda mais a acção, como Hannah Arendt demonstrou de modo notável, "exigirem ser contadas" 40 . A este nível, a narrativa está verdadeiramente implicada na nossa própria tomada de consciência mais imediata do viver em conjunto, verdadeiramente envolvida nas estruturas temporais reguladoras do domínio prático, na medida em que estas, justamente, não ganham sentido senão na troca de "histórias de vida".

Ora, a este nível de pré-compreensão, segundo Ricoeur, "o paralelismo entre a prática do tempo e a prática do espaço [já] é notável"41. De facto, assim como a narrativa se cola à necessidade vital de ordenar as pequenas e grandes preocupações, percalços ou inquietações para assim dizer "o quem da acção", assim também o projecto arquitectural se cola à necessidade vital de dizer o habitar fundamental, que radica no que Husserl denominou por Lebenswelt: o mundo da vida. A arquitectura vem ordenar os vários desassossegos que, na relação ao espaço, exigem ser contados e só o podem chegar a ser através das estruturas espaciais que regulam implicitamente o habitar: o tecto que protege, os limites da casa e a ordenação das suas partes através de um esboço de especialização das divisões, etc. De algum modo, trata-se nestes exemplos de ponderar a vocação narrativa de um habitar fundamental que reclama ser narrado e, portanto, apenas na coerência do arranjo arquitectural chega ao sentido. Perceberemos ainda melhor o que está em causa neste ponto se alargarmos a nossa reflexão ao urbanismo, que completa a narrativa do habitar através de uma configuração das necessidades de circulação - numa trama ajustada de ruas, praças e cruzamentos - complementares às do abrigo. Assim exigem a casa e o caminho serem contados; assim reclama

${ }^{37}$ RICOEUR, P., “Architecture et narrativité", p. 44.

${ }^{38}$ RICOEUR, P., Temps et récit, I, p. 87. Cf. PORTOCARRERO, M. L. Horizontes da Hermenêutica em Paul Ricoeur, pp. 60 e ss. ID, "Narrativa e Configuração da Identidade em Paul Ricoeur", pp. 269 e ss.

39 RICOEUR, P., “Architecture et narrativité”, p. 45.

${ }^{40}$ Cf. RICOEUR, P, Temps et récit, III, Seuil, Paris, 1985, p. 274, n.

${ }^{41}$ RICOEUR, P., “Architecture et narrativité”, p. 45. 
o espaço humano ser dito como habitar "feito de ritmos, de paragens e de movimentos, de fixações e de deslocações."42

Se levarmos ainda mais longe a análise, um outro aspecto surpreenderá: mesmo ao nível da pré-compreensão urge entender que a aproximação entre narratividade e arquitectura, mais do que simples analogia, é reveladora de uma significativa mistura. Não é difícil demonstrá-lo. Basta, para tanto, sublinhar os signos patentes de tal mescla: note-se, antes de mais, que "qualquer história de vida se desenrola num espaço de vida" e que a narrativa de conversação, com as suas trocas de memórias, é sempre "coextensiva" a percursos que se desenham através de lugares precisos; ou seja, uma história de vida está sempre ligada a um espaço que se partilha - espaço que nunca é apenas metafórico, mas concreto e material. Por outro lado, o espaço construído "consiste num sistema de gestos e ritos" que polarizam as mudanças temporais, que seguem trajectos afectivos, que sintetizam os lugares onde qualquer coisa das interacções maiores da vida acontece $^{43}$. Desde logo ao nível da pré-figuração habitamos, pois, uma cronotopia (Baktine) que reclama ser narrada, configurada, construída.

A Mimésis II é o acto de configuração narrativa propriamente dito que, afastando-se do contexto da vida quotidiana, institui, pela escrita e pela técnica narrativa, com os seus respectivos códigos, a esfera da obra literária. Segundo Ricoeur, tal acto de configuração comporta um triplo ponto de apoio ${ }^{44}$. Por um lado, a "intriga" (mise-en-intrigue), o muthus de Aristóteles, que consiste em construir uma história através da junção criativa de eventos isolados e confusos de modo a formar uma trama - trame, dirão os franceses; intreccio, dirão os italianos; "enredo", dirão os portugueses. E a função principal de tal enredo é sobretudo a de representar a acção ${ }^{45}$. Trata-se da característica mais definidora da narrativa e o que faz dela um existencial fundador da nossa relação ao tempo: a narrativa é capaz de sintetizar o heterogéneo, fazer concordar o discordante e, deste modo, transformar uma sucessão de instantes numa história com "princípio, meio e fim". Por outro lado, o acto de "configuração" implica um compromisso com a "inteligibilidade", isto é, com a tentativa de dar um sentido ao que, de outro modo, mais não seria do que uma simples sucessão inextrincável de ocorrências confusas, mudas ou fragmentadas. Finalmente, o acto de "configuração" consigna uma operação dinâmica de "intertextualidade" que consiste na confrontação de narrativas, sempre

42 Ibidem p. 45.

${ }^{43}$ Ibidem p. 47, passim.

44 Ibidem, 1. c.

${ }^{45}$ Cf. PORTOCARRERO, Maria Luísa, "Narrativa e Configuração da Identidade em Paul Ricoeur", pp. 58; 61. 
fértil e esclarecedora seja pela verificação do que as separa, seja pela comparação do que as aproxima.

Segundo Ricoeur, uma vez mais, algo de similar se passa ao nível da "configuração" do espaço realizada pela arquitectura e pelo urbanismo no momento em que constroem o enredo que conta, através do construído, a ocupação do espaço, os fluxos de trânsito, as necessidades habitacionais, a vocação da cidade, as urgências de mobilidade, a importância dos locais de lazer, as relações entre o centro e a periferia, etc. Nestas narrativas, um compromisso evidente com o sentido é evidente (promover o bem-estar, aumentar a mobilidade, rentabilizar os recursos); tanto quanto o facto de cada etapa do projecto arquitectural ou urbanístico promover uma dinâmica de "intertextualidade", ao confrontar-se com outros projectos, influências, escolas e tendências. E note-se - aspecto decisivo para Ricoeur - que é mais do que uma simples aproximação metafórica o que nestas semelhanças se pode e se deve, em derradeira análise, encontrar. Efectivamente, há que compreender que o projecto arquitectural, ao configurar o espaço, exibe, de direito, "uma dimensão temporal e narrativa"46: na nossa cronotopia, para usar uma outra vez o conceito de Baktine, cruzam-se valores narrativos e arquitectónicos ao ponto de ser legítimo falar, segundo Ricoeur, de "narratividade arquitectónica" 47 . De facto, a síntese temporal do heterogéneo que, como nos mostra Ricoeur em Temps et récit, é o traço maior da intriga, tem o seu equivalente numa idêntica "síntese espacial do heterogéneo" 48 promovida pela arquitectura. $\mathrm{O}$ projecto arquitectural visa criar peças onde diversas variáveis, tais como as células de espaço, as formas-massa, as superfícies limite, encontram uma "unidade suficiente", uma expressão com "princípio, meio e fim", uma ordenação criativa - como se o espaço não pudesse ser reconhecido senão através do projecto que, ao juntar ordenadamente diferentes elementos espaciais, nos permite configurar a nossa experiência confusa, informe ou muda do espaço.

É pois forçoso notar que a obra arquitectónica incorpora o tempo exemplar da narrativa no espaço, do mesmo modo que a intriga se encontra sempre "na via da sua transposição do tempo para o espaço". Esta incorporação - que o arquitecto, ao construir o seu projecto, realiza ao partilhar a mesma intenção de coerência discordante que habita o gesto do narrador ${ }^{49}$ - é evidente, desde logo, no facto de um edifício se construir ao longo de um tempo por vezes longo: cada edifício é "memória petrificada

\footnotetext{
${ }^{46}$ RICOEUR, P., “Architecture et narrativité”, p. 47

${ }^{47}$ Ibidem, p. 48.

48 Ibidem, 1.c.

49 Ibidem, 1.c.
} 
do edifício a construir-se." 50 Tal incorporação também se encontra no gesto de inscrição que aproxima o construtor do narrador em redor de uma mesma intenção de inteligibilidade, de um mesmo desejo de realizar a passagem do inextrincável ao compreensível: assim como a escrita assegura a sobrevivência e a duração das "coisas" contadas, os edifícios perduram no tempo graças à durabilidade dos materiais que fazem durar determinada inscrição de uma coesão e coerência arquitectónica - coerência e coesão essas que são, justamente, configuração narrativa do espaço humano. $\mathrm{O}$ acto arquitectural dobra, enfim, a "temporalidade exemplar" da narrativa na medida em que o seu gesto de configuração comporta também uma dimensão de "intertextualidade": "do mesmo modo que a narrativa tem o seu equivalente no edifício, o fenómeno de intertextualidade tem o seu equivalente na rede de edifícios já lá que contextualizam o novo edifício." ${ }^{51}$ Cada edifício se erige no espaço já construído da cidade, num momento histórico preciso e, como é claro, num lugar preciso envolvido por edifícios que o precederam e que serão mais ou menos diferentes, mais ou menos semelhantes, desenhando com o novo edifício seja novos contrastes, seja novas conjugações. Segundo Ricoeur, o arquitecto deve, pois, tal como o escritor que conta uma nova história num novo livro, fazer jogar o seu gesto de inscrição no limiar das "relações entre inovação e tradição", na medida em que a sua intenção de configuração deve traçar-se "depois", "segundo", ou "contra" uma tradição já arquivada na cidade. E não é este um arquivo qualquer: dele fazem parte construções de diferentes épocas e com diferentes cargas de memória, ruínas e monumentos mais ou menos preservados, habitações comuns e lugares celebrados, zonas de trânsito e áreas de lazer, vazios urbanos e cruzamentos - todos com a "sua" história, função ou vocação. Tal como uma nova personagem numa história que já começou e promete desenvolvimentos inesperados, o modo como cada nova construção se inscreve, nomeadamente, na cidade continuará necessariamente a narrar, então, diferentes maneiras de significar o antigo e o novo, o simbólico e o funcional, o emotivo e o económico, o familiar e o político.

Deste modo, algo de decisivo se torna claro: mais do que compreender simplesmente o acto de habitar como o pressuposto do construir, é fundamental entender a que ponto o construir toma a cargo o habitar - e a que ponto o faz, precisamente, para que a configuração que opera alcance o seu sentido mais completo e possa, finalmente, restituir ao espaço o seu significado mais profundo. Um aspecto importante deve, no entanto, ser desde logo sublinhado: tal significado não se encontra na

\footnotetext{
50 Ibidem, 1.c.

51 Ibidem, 1.c.
} 
literalidade do construído - do mesmo modo que o mundo dos textos não se encontra no sentido literal do que está escrito. É necessário que aquele que habita o edifício ou percorre as ruas da cidade, no encontro com o construído, contribua para libertar o respectivo sentido. O mesmo é dizer que o sentido de um espaço humano não se encontra sobre a superfície do construído, mas, outrossim, na sua apropriação formadora por parte daquele que só habita um espaço humano na medida em que é capaz de "refazer a memória do construir" 52 e de reflectir o seu habitar - o que, precisamente, só é possível através de uma leitura, sempre inacabada, das possibilidades de sentido que o mundo da obra construída disponibiliza no encontro com as necessidades, esperanças e inquietações daquele que habita. Eis assim enunciado um estádio de "refiguração" do construído que devemos, segundo Ricoeur, aproximar estreitamente ${ }^{53}$ da Mimèsis III exposta em Temps et récit.

Nesta obra, como é sabido, a "refiguração" assinala a seguinte ideia: a configuração operada pela narrativa não se cumpre senão quando é "restituída ao tempo do agir e do sofrer" 54 . A Mimèsis III desenha-se, pois, nos lugares em que as possibilidades de sentido do mundo do texto se libertam no encontro com o mundo do leitor ${ }^{55}$.

Retomado e assumido, redito e apropriado no acto de 1 er ${ }^{56}$, o texto oferece ao "seu" leitor um laboratório de possibilidades de sentido que são outras tantas ocasiões preciosas do leitor encontrar modos alternativos de compreender a sua própria situação - aquela com a qual chega ao texto à procura de um rumo para o seu agir inquieto. Por esta razão se deve sublinhar que a compreensão de um texto se completa sempre na compreensão de si do sujeito que procura orientar a sua acção; e de nenhum outro modo tal se pode fazer melhor do que, precisamente, através das propostas de sentido que o texto oferece a quem lê. É com tais propostas

52 Ibidem, 45.

53 Ibidem, p. 49: «Le rapprochement entre récit et architecture se fait plus étroit, jusqu'au point où le temps raconté et l'espace construit échangent leurs significations.»

${ }^{54}$ Cf. PORTOCARRERO, Maria Luísa, "Narrativa e Configuração da Identidade em Paul Ricoeur", p. 67.

55 RICOEUR, P., Temps et récit, I, p. 109 : « Généralisant au-delà d'Aristote, je dirai que mimèsis III marque l'intersection du monde du texte et du monde de l'auditeur ou du lecteur. L'intersection, donc, du monde configuré par le poème et du monde dans lequel l'action effective se déploie et déploie sa temporalité spécifique».

${ }^{56}$ RICOEUR, P., Du texte à l'action. Essais d'herméneutique II, Seuil, Points Essais, 1986, p. 170: «Lire, c'est en toute hypothèse enchaîner un discours nouveau au discours du texte. Cet enchaînement d'un discours à un discours dénonce, dans la constituition même du texte, une capacité originelle de reprise qui est son caractère ouvert. L'interprétation est l'aboutissement concret de cet enchaînement et de cette reprise». 
de sentido, por vezes polémicas e heterodoxas, que o leitor se confronta; e seja esse confronto passivo ou reticente, escandaloso ou de acolhimento "activamente cúmplice" 57 , o texto abre sempre o leitor à diferença, ao que pode descentrá-lo, assim como a experiências temporais possíveis que serão sempre para ele a ocasião de clarificar a textura temporal da sua própria vida. Tocado pela palavra, o leitor, no momento de receber o mundo do texto, é interpelado e transformado na exacta medida em que, nesse encontro, passa por novas experiências de pensamento que lhe dão a oportunidade de levar consigo valores, escolhas, aspectos éticos de conduta que, de um modo ou de outro, o ajudarão a orientar e significar a sua acção. A intriga, o enredo que a narrativa constrói e o texto alberga, abre a um sujeito cuja natureza é historial as possibilidades mais radicais e inovadoras de se compreender melhor, de se compreender de outro modo, ou mesmo de se começar a compreender ${ }^{58}$.

Ora, segundo Ricoeur, tal possibilidade deve ser também a da narrativa arquitectural e urbanística: os projectos e construções arquitectónicas e urbanísticas que configuram o nosso horizonte num espaço humano devem cumprir plenamente o seu desígnio numa possibilidade de "refiguração"; ou seja, devem, enfim, abrir-se à leitura. O mesmo é afirmar que o fim último do projecto arquitectural só se alcança quando o construído nos oferece a todos - a quem habita ou percorre a cidade - a ocasião de "ler e reler os nossos lugares de vida a partir do nosso modo [propriamente humano] de habitar." 59 Assim dará o construir a última palavra ao habitar.

Com efeito, julgará Ricoeur, a realização de um projecto arquitectónico ou urbanístico apenas se cumpre, de certo modo, na recepção activa daqueles que o habitarão, daqueles que, portanto, não habitam senão retomando, assumindo, relendo activa e atentamente o envolvimento proposto por cada edifício, rua, praça, ou malha urbana. Do que aqui se trata não é, obviamente, de uma qualquer crítica exterior ao trabalho do arquitecto ou do urbanista; o que está em questão é, isso sim, sublinhar a que ponto na construção arquitectónica e urbanística se joga a ocasião de o sujeito que habita se compreender melhor, se compreender de outro modo ou se começar a compreender. E um habitar assim representa realmente uma resposta, uma "riposta ao construir sobre o modelo do acto agnóstico de leitura" 60 : em cada edifício ou rua, em cada cruzamento ou praça, o sujeito, cuja natureza é também espacial, deve confrontar-se com propostas alternativas, polémicas, novas de dizer o espaço; e neste laboratório de

\footnotetext{
${ }^{57}$ RICOEUR, P., « Architecture et narrativité », p. 49.

58 RICOEUR, P., Du texte à l'action, p. 170.

${ }^{59}$ RICOEUR, P., «Architecture et narrativité », p. 49.

60 Ibidem, p. 51.
} 
possibilidades ganhará, no encontro com a diferença, novas possibilidades de sentido para orientar a sua acção.

Reforcemos, com Ricoeur, a tese aqui decisiva: a compreensão de si é possível através da leitura de textos $e$ através da leitura atenta e plural da cidade - desse "livro de pedra", como lhe chamou W. Benjamin. Pelas suas possibilidades de sentido somos tocados e transformados nas ocasiões em que se abre à leitura daqueles que o habitam, daqueles que nele reconhecem (num acordo significativo entre a coisa construída e o texto literário ${ }^{61}$ ) modos alternativos de significar a experiência do espaço humano. As sínteses do heterogéneo, as concordâncias discordantes, as justaposições de dissemelhanças que a cidade é capaz de inscrever, de pôr em trama, de que a cidade é o enredo, são mundos de significação indispensáveis à compreensão do modo humano de estar no mundo. A justaposição de estilos arquitectónicos, a junção ou o confronto entre o velho e o novo, as relações entre o monumental e o provisório, o simbólico e o funcional, entre o centro e a periferia, o culturalmente familiar e o estrangeiro, estruturam, de facto, ligações inovadoras ao espaço que, por seu turno, se confrontam com as expectativas do sujeito e, nesse encontro polémico, lhe prometem ensejos outros de configurar e reconfigurar a condição humana, de reescrever a realidade, de representar acção e orientar $\mathrm{o}$ agir.

O gesto de compreensão de si e de orientação de si ganham força na releitura incessante do livro que é a cidade; nele se ensaiam múltiplas formas de misturar o passado, o presente e o futuro (a velha igreja envolvida por uma praça renovada, mutuamente se provocando e sublinhando), de conjugar o que é diferente (um prédio antigo restaurado com materiais e formas modernas; um edifício provocador que marca a paisagem pela diferença), de cruzar o conhecido e o desconhecido (o comércio, "porta com porta", de produtos vindos de todo o mundo), de fazer jogar a dialéctica do socius e do próximo, de juntar a vida e a morte (o cemitério que a cidade lentamente envolve), de preservar o antigo sem recear o novo, de tolerar a diferença, de cuidar do que terá um fim. Mas os sentidos assim disponibilizados, deve sublinhar-se, apenas se libertam se a interpretação da cidade se completar na interpretação de si daquele que habita. Eis, julgamos, a tese de fundo que Ricoeur pretende sustentar: o enredo que a cidade abre à leitura, "as histórias de vida das quais os monumentos e todos os edifícios albergam o vestígio"62, as atitudes, os valores e as escolhas que a organização da "malha urbana" inscreve sobre o espaço dão lugar, de facto, a novas e necessárias leituras dos horizontes

${ }^{61}$ Ibidem, 1. c.

${ }^{62}$ Ibidem, 1. c. 
geográfico ${ }^{63}$, histórico, social e político nos quais a nossa vida prática se situa, constantemente à procura de renovada orientação.

\section{Espaço e Memória}

Se a nossa análise estiver correcta, deve explicitar-se a que ponto é, enfim, mais do que uma simples aproximação entre narrativa e arquitectura o que, segundo Ricoeur, há que pensar. Porventura impõe-se meditar uma efectiva reversibilidade já que, no limite, "o tempo narrado e o espaço construído trocam os seus significados." 64

O tema da memória, segundo Ricoeur, revela-se particularmente esclarecedor a este propósito. Na cidade, a memória pode ter lugar, pode encontrar o seu lugar. Tal é verdade ao nível das nossas experiências mais quotidianas quando, por exemplo, a recordação de alguém é dita através de um espaço: "ainda me lembro de o ver sentado naquela mesa de café...", ou "... quando atravessava a estrada". Igualmente ao nível da história dos povos e nações a memória se guarda "escrita" no espaço: quando se preserva uma ruína que recorda feridas da história, quando se assinala, o "aqui" onde algozes e vítimas se encontraram e a voz do passado não pode ser reprimida. O tempo narra-se, então, também através do espaço e o espaço através do tempo. De facto, como escreve Ricoeur, épocas diferentes, com os seus valores e histórias, concretizações e expectativas, recapitulam-se e permanecem "em reserva onde estão inscritos". Mas para que o tal livro de pedra, que guarda inscrições e através delas narra o passado, se ofereça à reconfiguração justa, é preciso que os traços, os vestígios das actividades e sofrimentos, das conquistas e derrotas do passado, que os lugares onde a memória pode ter lugar não sejam apenas resíduos, mas testemunhos reactualizados do passado - de um passado que, justamente, "já não é mas foi" ${ }^{2}$. É bem este ter sido que o livro de pedra que dura deve salvar tanto do esquecimento activo, como do perigo da repetição ${ }^{66}$. Neste sentido, a refiguração da cidade deve nutrir-

${ }^{63}$ Cf. RICOEUR, P., La mémoire, l'histoire, l'oubli, p. 188 e ss.

${ }^{64}$ RICOEUR, P., “Architecture et narrativité”, p. 49.

65 Ibidem, p. 51.

${ }^{66}$ Aqui, evidentemente, Ricœur tem em mente as contribuições clássicas de Freud para o estudo da resistência da memória em face de acontecimentos traumáticos; Ricœur pensa, em particular, na oposição entre trabalho de memória e « compulsion de répétition » (Ibidem, p. 51). Cf. RICOEUR, P., La mémoire, l'histoire, l'oubli, o.c., p. 84 e ss. Ricœur faz referência aos textos de Gesammelte Werke de Freud, t. X, S. Ficher Verlag, 1913-1917, pp. 126-136. 
-se de uma memória-reconstrução que permita acolher o diferente "com curiosidade e com a preocupação de reorganizar o antigo com vista a dar lugar ao novo." ${ }^{\prime 67}$

A cidade deve fazer-se promessa de si mesma e, deste modo, arrancar a memória da mesmidade estéril, da nostalgia paralisante, do ressentimento podre, como da vã glória ${ }^{68}$. E, para tal, é necessário que a releitura sempre inacabada das nossas cidades seja constantemente o momento de um trabalho de memória e de um trabalho de luto - trabalho de luto que veja nas ruínas de épocas perdidas a ocasião de "se compreender de outras maneiras", a ocasião para aceitar o irreparável, assumir o irreconciliável e, enfim, acolher através do indecifrável das nossas cidades o indecifrável dos nossos destinos.

Talvez assim se compreenda um pouco das razões que levaram Ricoeur a terminar o seu artigo "Architecture et narrativité" com uma referência ao flâneur de Benjamin. É que o flâneur, efectivamente, está em consonância com o tempo e o espaço da cidade; mais: ele sabe que o único meio de fazer a verdadeira experiência da cidade - nomeadamente, a experiência estética que procura insaciavelmente - é fazendo recorrentemente o luto do familiar e do quotidiano para, através dele, ter a ocasião de se compreender - ainda e sempre através da cidade - de outro modo, ou de modo novo. A rendição conscientemente passiva aos movimentos aleatórios da turba pode, então, ser entendida como gesto de uma memória-reconstrução: emerso no véu da multidão através do qual a cidade familiar se "desrealiza" progressivamente, se metamorfoseia numa fantasmagoria, o flâneur acolhe uma narrativa outra da cidade. É, pois, ainda como leitor que deambula ao acaso pelas folhas do livro de pedra - e todos sabemos como a sabedoria do acaso muitas vezes nos conduz o olhar até uma linha iluminadora.

${ }^{67}$ RICOEUR, P., “Architecture et narrativité”, p. 51.

${ }^{68}$ RICOEUR, P., « Le bon usage des blessures de mémoire», http://www.fondsricoeur. $\mathrm{fr} /$ photo/temoin(4).doc. 